\title{
Article \\ Self-Assembled Corn-Husk-Shaped Fullerene Crystals as Excellent Acid Vapor Sensors
}

\author{
Zexuan Wei ${ }^{1,2}$, Jingwen Song ${ }^{2}$, Renzhi Ma ${ }^{2}$, Katsuhiko Ariga ${ }^{1,2}$ and Lok Kumar Shrestha ${ }^{2, *}$ (I) \\ 1 Department of Advanced Materials Science, Graduate School of Frontier Sciences, The University of Tokyo, \\ 5-1-5 Kashiwanoha, Chiba 277-8561, Japan; z.wei20a@ams.k.u-tokyo.ac.jp (Z.W.); \\ ARIGA.Katsuhiko@nims.go.jp (K.A.) \\ 2 International Center for Materials Nanoarchitectonics (WPI-MANA), National Institute for Materials \\ Science (NIMS), Namiki 1-1, Ibaraki, Tsukuba 305-0044, Japan; songjingwen566@gmail.com (J.S.); \\ MA.Renzhi@nims.go.jp (R.M.) \\ * Correspondence: SHRESTHA.Lokkumar@nims.go.jp; Tel.: +81-29-860-4809
}

check for updates

Citation: Wei, Z.; Song, J.; Ma, R.;

Ariga, K.; Shrestha, L.K.

Self-Assembled Corn-Husk-Shaped Fullerene Crystals as Excellent Acid Vapor Sensors. Chemosensors 2022, 10, 16. https://doi.org/10.3390/

chemosensors10010016

Academic Editors: Arcady Zhukov, Tatiana Perova and

Valentina Zhukova

Received: 29 November 2021

Accepted: 31 December 2021

Published: 2 January 2022

Publisher's Note: MDPI stays neutral with regard to jurisdictional claims in published maps and institutional affiliations.

Copyright: (c) 2022 by the authors. Licensee MDPI, Basel, Switzerland. This article is an open access article distributed under the terms and conditions of the Creative Commons Attribution (CC BY) license (https:/ / creativecommons.org/licenses/by/ $4.0 /)$.

\begin{abstract}
Low-molecular-weight acid vapors cause aging and destruction in material processing. In this paper, facile fabrication of novel corn-husk-shaped fullerene $\mathrm{C}_{60}$ crystals (CHFCs) through the dynamic liquid-liquid interfacial precipitation method is reported. The CHFCs were grown at the liquid-liquid interface between isopropyl alcohol (IPA) and a saturated solution of $\mathrm{C}_{60}$ in mesitylene under ambient temperature and pressure conditions. The average length, outer diameter, and inner diameter of CHFCs were ca. $2.88 \mu \mathrm{m}, 672 \mathrm{~nm}$, and $473 \mathrm{~nm}$, respectively. X-ray diffraction (XRD) analysis showed the CHFCs exhibit a mixed face-centered cubic $\left(f_{c c}\right)$ and hexagonal-close pack $(h c p)$ crystal phases with lattice parameters $a=1.425 \mathrm{~nm}, V=2.899 \mathrm{~nm}^{3}$ for $f c c$ phase and $a=2.182 \mathrm{~nm}$, $c=0.936 \mathrm{~nm}, a / c$ ratio $=2.33$, and $V=3.859 \mathrm{~nm}^{3}$ for $h c p$ phase. The CHFCs possess mesoporous structure as confirmed by transmission electron microscopy (TEM) and nitrogen sorption analysis. The specific surface area and the pore volume were $c a .57 .3 \mathrm{~m}^{2} \mathrm{~g}^{-1}$ and $0.149 \mathrm{~cm}^{3} \mathrm{~g}^{-1}$, respectively, are higher than the nonporous pristine fullerene $C_{60}$. Quartz crystal microbalance (QCM) sensing results show the excellent sensing performance CHFCs sensitive to acetic acid vapors due to the enhanced diffusion via mesoporous architecture and hollow structure of the CHFCs, demonstrating the potential of the material for the development of a new sensor system for aliphatic acid vapors sensing.
\end{abstract}

Keywords: fullerene; corn-husk; liquid-liquid interface; self-assembly; vapor sensing; acid vapors; quartz-crystal microbalance

\section{Introduction}

Volatile organic acids, mostly known as low-carbon number corrosive acids such as formic acid, acetic acid, are considered as detrimental factors for human diseases [1], beverage industry [2-4], and metal-aging protection [5,6]. Efficient, price-reasonable, sensitive sensor materials are crucial for health diagnosing [7] and environmental quality monitoring [8,9]. A selective acid detector is supposed to discriminate the aimed compound from others, which are of similar molecule weight and chemical properties like formic acid and acetic acid. However, current metal-oxide or nitride electrode sensors [10-12] are only possible in high-temperature environments. Carbon-based nanostructures have attracted significant attention in academia as a fabulous tool for developing gas sensors $[13,14]$ which have good prospects for low-energy consumption and cost-effective properties.

Discovered in 1985, fullerene, an allotrope of carbon, is a cage-structured molecule with excellent redox, optoelectronic properties $[15,16]$, which function as an ideal zerodimensional building block nanoarchitecture, and has already been broadly applied in sensing technologies [17-21]. Out of the demand for synthesis and fabrication of functional materials such as energy storage, environment protection, and device technology, 
self-assembly of fullerene has been heatedly discussed [22-25]. Used in manipulating atoms and molecules, the self-assembly of fullerene promotes the functions of the synthesized clusters used in devices and sensors. Varieties of synthesizing methods have been developed to design controlled crystalline fullerene morphology, such as the template synthesis method [26], photo-assisted crystal growth method [27], and solvent evaporation method [28]. Out of these methods, the liquid-liquid interfacial precipitation (LLIP) method initiated by Miyazawa [29] enables a range of dimensionally-controlled nanostructures, such as one-dimensional (1D) nanotubes, two dimensional (2D) [30,31], three dimensional (3D) cubes [18], and nanospheres [32]. Such diversity of nanostructures exhibits enhanced supramolecular properties [33,34]. The solvated 3D fullerene cube can grow into a hierarchical structure with mesoporous nanorods on its cube surface upon being washed by isopropanol alcohol [18], whose vapor-phase sensing performance has been promoted after structural rearrangement. As reported by Hsieh and coworkers [35], the fullerene crystals of $1 \mathrm{D} \mathrm{C}_{60}$ nanotubes, $2 \mathrm{D} \mathrm{C}_{60}$ nanosheets, and $3 \mathrm{D} \mathrm{C}_{70}$ cubes, after the post-assembly process by chemical etching, are equipped with higher selectivity for low-carbon number acid rather than aromatic acid.

This study reports the vapor sensing performances of the self-assembled corn-huskshaped fullerene $\mathrm{C}_{60}$ crystal (CHFCs) fabricated by a dynamic liquid-liquid interfacial precipitation (DLLIP) method under ambient temperature and pressure conditions. Most fullerene-based sensors are highly selective for aromatic vapors, such as aniline or toluene, because of their relatively higher solubility in aromatic solvents than that of aliphatic or hydroxyl compounds [17]. However, on account of the unique half-opened, tube-like structure and its typical tiny pore size, compared to pristine $\mathrm{C}_{60}$, it is notable that these CHFCs exhibit highly sensitive sensing performance for acetic acid vapor. Therefore, it is believed that this unique fullerene self-assembly is a prospective candidate for volatile acid-sensing system materials.

\section{Materials and Methods}

\subsection{Materials}

Pristine fullerene $\mathrm{C}_{60}\left(\mathrm{pC}_{60}\right)$ powder (purity $99.9 \%$ ) was purchased from BBS Chemicals, Chimes Drive, Houston, TX, USA. Isopropyl alcohol (IPA, purity 99.7\%) and mesitylene (purity 99.8\%) were purchased from the Wako Chemical Corporation, Tokyo, Japan.

\subsection{Synthesis of Corn-Husk-Shaped Fullerene Crystals (CHFCs)}

A saturated solution of fullerene $\mathrm{C}_{60}$ was prepared by dissolving excess $\mathrm{pC}_{60}$ powder $(60 \mathrm{mg})$ in mesitylene $(50 \mathrm{~mL})$. Undissolved excessive fullerene was removed by the filtration. Using the DLLIP method, the self-assembled fullerene $\mathrm{C}_{60}$ crystals were synthesized. Typically, isopropyl alcohol (IPA: $5 \mathrm{~mL}$ ) was quickly added into the freshly prepared saturated solution of $\mathrm{C}_{60}$ in mesitylene ( $\left.1 \mathrm{~mL}: 0.999 \mathrm{mg} / \mathrm{mL}\right)$, immediately followed by a vigorous hand-shaking for about $3 \mathrm{~s}$. The mixture was incubated at $25^{\circ} \mathrm{C}$ for $15 \mathrm{~min}$ avoiding any external mechanical disturbances. The CHFCs precipitates were washed with IPA $(5 \mathrm{~mL})$ three times to remove the organic solvent and finally separated from the mixture by centrifugation and dried in a vacuum oven at $70^{\circ} \mathrm{C}$ for $3 \mathrm{~h}$.

\subsection{Characterizations}

The CHFCs were characterized by scanning electron microscopy (SEM, operating at $10 \mathrm{kV}$, Hitachi S-4800, Tokyo Japan), scanning transmission electron microscopy (STEM, operating at $30 \mathrm{kV}$, Hitachi S-4800, Tokyo Japan), transmission electron microscopy (TEM, operated at $300 \mathrm{kV}$, JEM-3100 JEOL, Tokyo, Japan), powder X-ray diffraction (operated at $40 \mathrm{kV}, \mathrm{Cu}-\mathrm{K} \alpha$ radiation $(\lambda=0.1541 \mathrm{~nm})$ RINT2000 diffractometer, Rigaku, Tokyo, Japan), Fourier transform infrared (FT-IR) spectroscopy (ATR-FTIR, Nexus 670, Tokyo, Japan), Raman scattering (NRS-3100 Raman spectrometer, JASCO, Tokyo, Japan), and X-ray photoelectron spectroscopy (XPS; Thermo Electron Co. Karlsruhe, Germany, a monochromatic $\mathrm{Al}-\mathrm{K} \alpha$ radiation of photon energy $15 \mathrm{keV}$ ). The electron microscopy samples were prepared 
on carbon-coated copper grids by dropping CHFCs suspension in IPA $(5 \mu \mathrm{L})$ and drying in a vacuum at $70{ }^{\circ} \mathrm{C}$. The surface texture properties, including surface area and pore volume, were studied by nitrogen sorption measurements (Autosorb-iQ2, Quantachrome, Boynton Beach, FL, USA). The CHFCs ( 20 mg) were degassed heating at $120{ }^{\circ} \mathrm{C}$ for $24 \mathrm{~h}$ before recording the nitrogen sorption isotherms.

\subsection{Vapor Sensing by Quartz Crystal Microbalance (QCM)}

The vapor sensing property of CHFCs was studied using a QCM technique. In this study, we monitored the frequency change in the Au-resonator loaded with CHFCs as QCM electrode exposed to different guest vapors by a resonance frequency of $9 \mathrm{MHz}$ (AT-cut). Note that the QCM electrode was stable in the air $( \pm 2 \mathrm{~Hz})$ over a recorded period of 10 min. QCM sensor electrode was prepared as follows: CHFCs $(1 \mathrm{mg})$ were dispersed in IPA $(1 \mathrm{~mL})$, and then the mixture was sonicated for $30 \mathrm{~s}$. Since the $\mathrm{C}_{60}$ molecule is stable in IPA, suspension of IPA will not lead to the morphology changing of the CHFCs. CHFCs suspension $(2 \mu \mathrm{L})$ was then drop cast onto the QCM electrode (Au resonator). For the contrast group of pristine $\mathrm{C}_{60}$, to get obvious frequency shift on $\mathrm{QCM}$, a larger volume $\mathrm{C}_{60}$ saturated solution of mesitylene $(5 \mu \mathrm{L})$ was drop casted onto the gold electrode. The electrodes were dried at $70{ }^{\circ} \mathrm{C}$ in a vacuum for $5 \mathrm{~h}$. The resulting QCM electrode was then plugged onto the instrument and then exposed to different solvents vapors $(10 \mathrm{~mL}$ in an opening container) at room temperature. The exposing experiments were conducted in a sealed chamber to create a saturated vapor atmosphere for absorption of respective vapors and to minimize the escaping of vapors during the frequency monitoring. After the frequency reached equilibrium, the chamber was removed for the desorption of vapors. The repeatability test of CHFCs as the QCM electrode was also performed during vapors' alternate absorption and desorption cycles by measuring the time dependence of frequency shift $(\Delta \mathrm{f})$. Similarly, all the QCM electrodes were prepared and the mass loaded on the QCM electrodes of the CHFCs on a single electrode was normalized to $1 \mu \mathrm{g}$.

The mass change $\mathrm{m}\left(\mathrm{g} \mathrm{cm}^{-2}\right)$ in the sample loaded on the QCM electrode can be measured by the quartz electrode's frequency shift $(\Delta \mathrm{f})$. The frequency change linear dependence of sample amount loaded on the QCM electrode can be calculated from the Sauerbrey equation:

$$
\Delta f=\left(\frac{2 f_{0}^{2}}{A \sqrt{\rho_{Q} \mu_{Q}}} \Delta m\right)
$$

where $f_{0}(\mathrm{~Hz})$ is the natural frequency of the quartz crystal, $\Delta m$ is mass change $(\mathrm{g}), A$ is area between electrodes $\left(\mathrm{cm}^{2}\right), \rho_{Q}$ is quartz density $\left(2.649 \mathrm{~g} \mathrm{~cm}^{-3}\right)$, and $\mu_{Q}$ is the shear modulus $\left(2.947 \times 1011 \mathrm{~g} \mathrm{~cm}^{-1} \mathrm{~s}^{2}\right)$.

\section{Results}

The surface morphology of the self-assembled CHFCs prepared by the dynamic liquid-liquid interface precipitation method (DLLIP) under the ambient conditions of pressure and temperature was studied by SEM analyses. Figure 1 shows SEM images and the corresponding size distributions of the CHFCs. The self-assembled fullerene nanostructure exhibits a corn-husk-shaped structure with a half-opening hollow structure in one end (Figure 1a-c). The length, outer diameter, and inner diameter distributions of CHFCs are estimated from one hundred randomly selected CHFCs. The histograms show uniform size distributions demonstrating a uniform crystal growth with an average length of $c a .2 .88 \mu \mathrm{m}$, an average outer diameter of $c a .672 \mathrm{~nm}$, and an average inner diameter of ca. $473 \mathrm{~nm}$, respectively (Figure $1 \mathrm{~d}-\mathrm{f}$ ). 

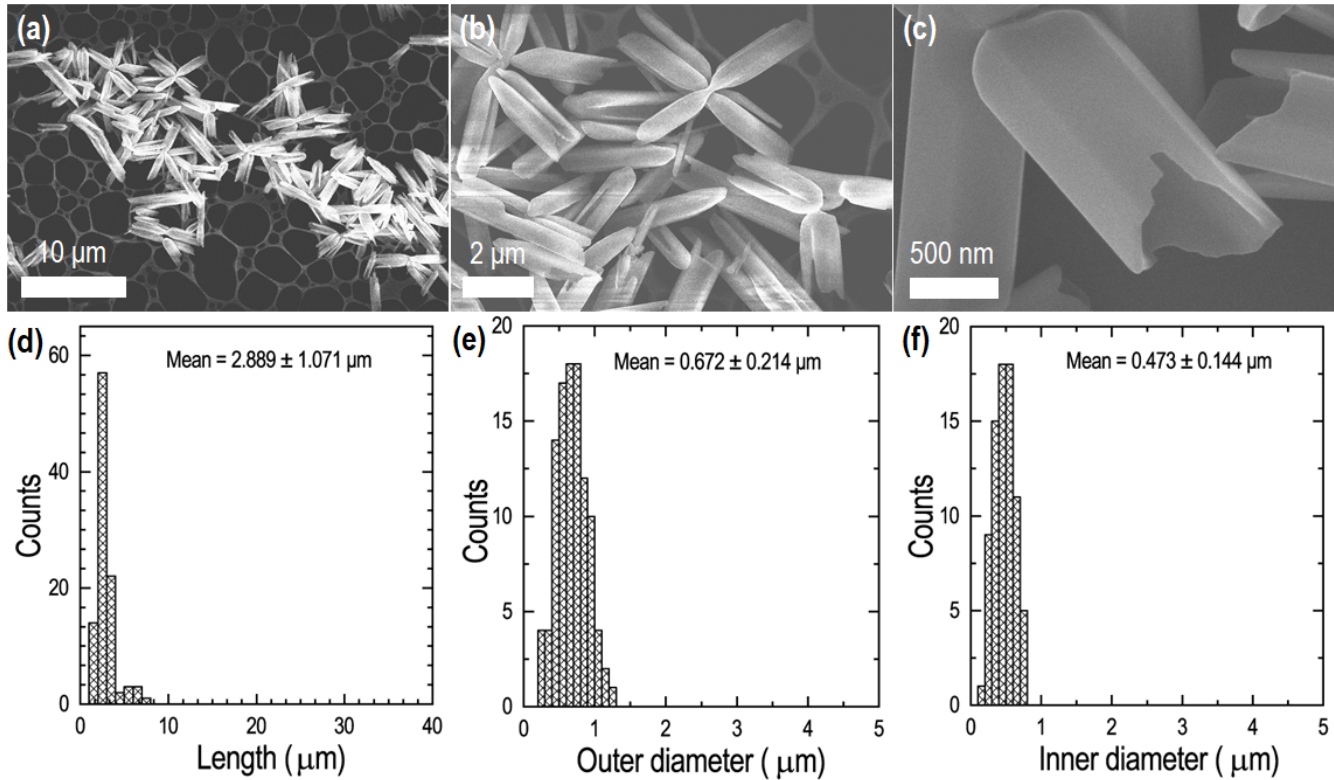

Figure 1. The surface morphology and size distribution of the CHFCs: (a-c) SEM images; (d) Histogram of the length distribution profile; (e) Histogram of the outer diameter distribution profile; (f) Histogram of the inner diameter distribution profile.

The scanning transmission electron microscopy (STEM) and TEM images revealed the hollow structure of the CHFCs (Figure 2a-d). High-resolution STEM images (Figure 2b) and TEM images (Figure 2c,d) confirm that the CHFC has a unique thin tubular wall with a half-opening structure in one end while the other has a solid structure. As seen in the HR-TEM, the CHFCs have microporous structures with crystalline pore walls (Figure 2e), which provide nano spaces required for the guest vapor adsorption, enhancing the gas sensing performance. Moreover, densely packed crystal lattice planes parallel to the CHFCs to the length of CHFC can be seen. The lattice spacing $c a$. $0.925 \mathrm{~nm}$ corresponds to the distance between (110) planes of the $h c p$ crystal phase [36,37].

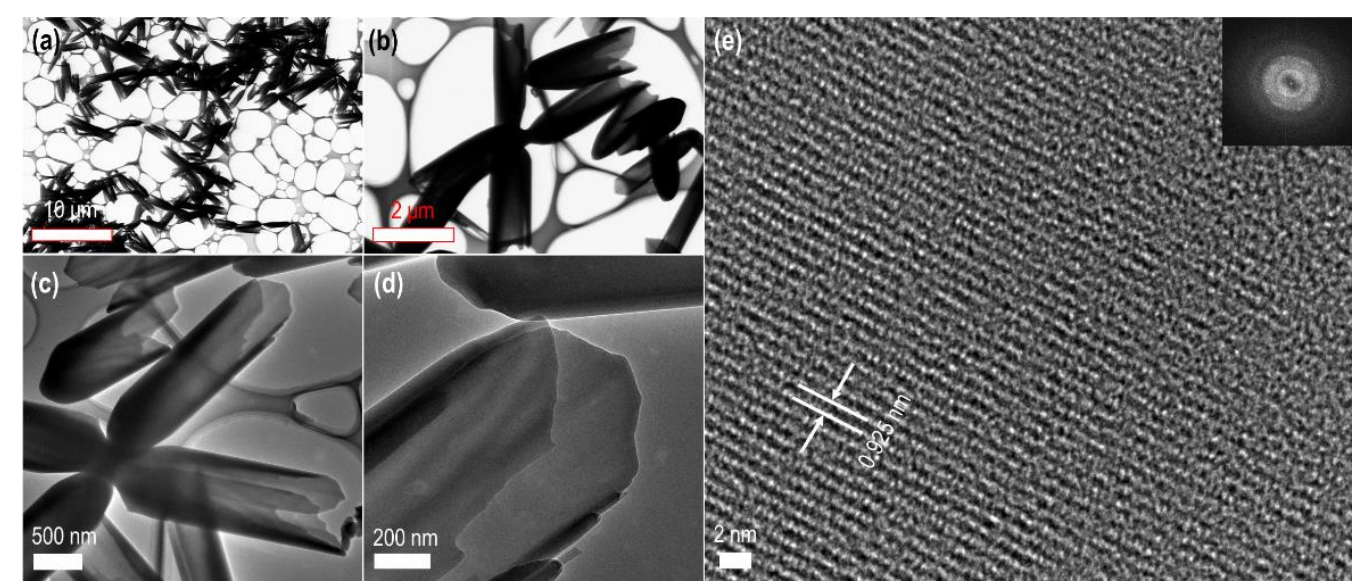

Figure 2. Electron microscopy observations of the CHFCs: (a,b) STEM images; (c,d) TEM images; (e) HR-TEM image with a selected area diffraction pattern in the inset.

Previously, it has found that the precipitation from IPA and $\mathrm{C}_{60}$ mesitylene solution using static or modified LLIP method results in the formation of 1D tubular structures at both the ends with a solid core at the center of the tubes [38]. Presently, DLLIP method is used, which initially assembled into cross-linked (X or Y-shaped) structures with hollow ends (Figure $2 b, c$ ). These cross-linked assemblies disassemble due to vigorous mechanical 
shaking by hand and result in the formation of CHFCs. Since the nuclei formation time for $\mathrm{C}_{60}$ precipitation is relatively short, usually within a few milliseconds, synthesis of the homogeneous CHFCs requires ultrafast addition of IPA into fullerene solution followed by vigorous handshaking to maximize the intermixing and interactions of IPA and mesitylene solution.

Structural characterization of the CHFCs was performed using the pXRD technique and compared the results with $\mathrm{pC}_{60}$ (Figure $3 \mathrm{a}$ ). The $\mathrm{pXRD}$ pattern shows a mixed facecentered cubic $(f c c)$ and hexagonal close-pack $(h c p)$ phase of the CHFCs. The diffraction peaks at diffraction angles of $10.7,17.6$, and $20.66^{\circ}$, correspond to the (111), (022), and (024) planes of the $f_{c c}$ phase, which is similar to that of the $\mathrm{pC}_{60}$. While, the diffraction peaks at $7.4^{\circ}, 8.58^{\circ}, 10.22^{\circ}, 10.76^{\circ}, 12.16^{\circ}, 14.72^{\circ}, 19.24^{\circ}$ correspond to the (110) (200) (101) (210) (300) (310) (410) planes of the $h c p$ phase. The lattice parameters of the $f c c$ crystal phase are ca. $a=1.425 \mathrm{~nm}, V=2.899 \mathrm{~nm}^{3}$. The lattice parameters of the $h c p$ phase are $c a . a=2.182 \mathrm{~nm}$, $c=0.936 \mathrm{~nm}, a / c$ ratio $=2.33, V=3.859 \mathrm{~nm}^{3}$, which are similar to the reported $h c p$ structures of $\mathrm{C}_{60}$ self-assemblies [38].
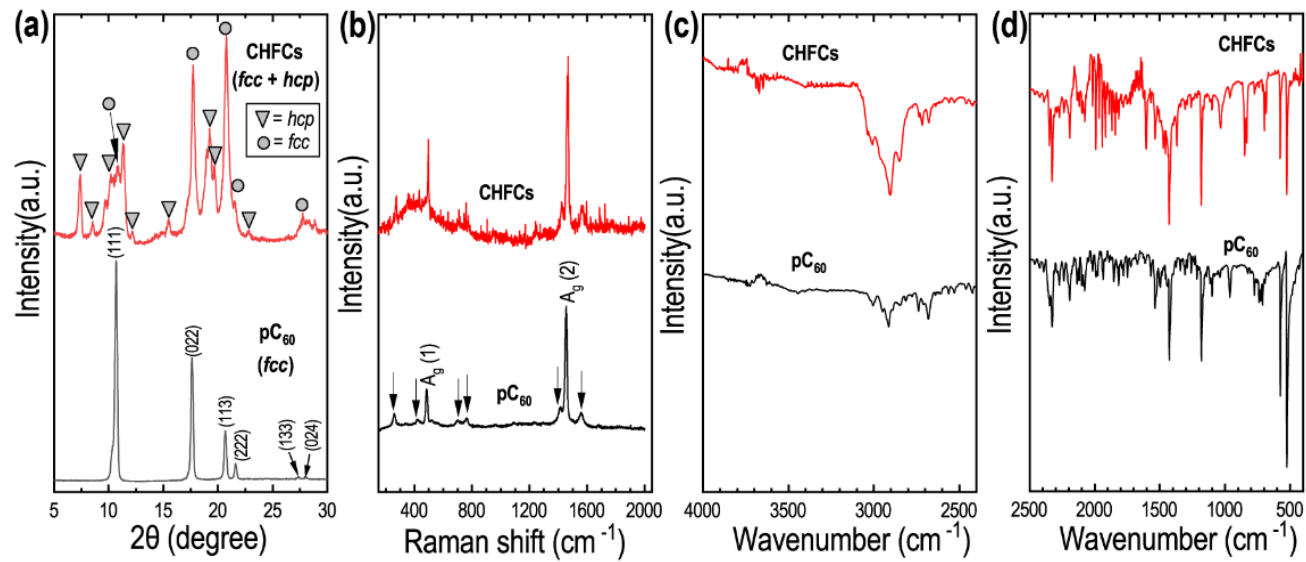

Figure 3. Characterizations of $\mathrm{pC}_{60}$ and the self-assembled CHFCs: (a) Powder X-ray diffraction (pXRD); (b) Raman scattering spectra; (c) FT-IR spectra in high wavenumber region; (d) Corresponding FT-IR spectra in low wavenumber region.

Raman scattering spectrum of the CHFCs is similar to that of $\mathrm{pC}_{60}$ (Figure $3 \mathrm{~b}$ ). Raman spectra showed two $\mathrm{A}_{\mathrm{g}}$ mode $\left(\mathrm{A}_{\mathrm{g}}(1)\right.$ breathing mode of peak at $495.5 \mathrm{~cm}^{-1}$, and $\mathrm{A}_{\mathrm{g}}(2)$ pentagonal pinch mode of peak at $\left.1464 \mathrm{~cm}^{-1}\right)$ and six $\mathrm{H}_{\mathrm{g}}$ vibration bands $\left(\mathrm{H}_{\mathrm{g}}(1), \mathrm{H}_{\mathrm{g}}(2)\right.$, $\mathrm{H}_{\mathrm{g}}(3), \mathrm{H}_{\mathrm{g}}(4), \mathrm{H}_{\mathrm{g}}(7)$ and $\mathrm{H}_{\mathrm{g}}(8)$ corresponding to the Raman peaks at 271, 431, 709.5, 771.5, $\left.1421,1566.5 \mathrm{~cm}^{-1}\right)$. Out of these Raman active bands, peak shift of $\mathrm{A}_{\mathrm{g}}(2)$ is a sensitive indicator of polymerization of $\mathrm{C}_{60}$ molecules and has been used as an analytical probe for the structural and optoelectronic properties of fullerene $C_{60}$ molecule [39]. Note that the $\mathrm{A}_{\mathrm{g}}(2)$ peak position of the $\mathrm{pC}_{60}$ does not shift in the CHFCs, suggesting the persistence of the free molecular rotation of $\mathrm{C}_{60}$ molecules in the self-assembled CHFCs. The Raman spectra reveal that $\mathrm{C}_{60}$ molecules make the majority of building blocks to form $\mathrm{CHFCs}$ nanostructure. Moreover, the laser irradiation during measurements did not cause polymerization of $\mathrm{C}_{60}$ molecules; self-assembled crystals keep in the molecular state without forming intermolecular bonding between the adjacent $\mathrm{C}_{60}$ molecules. The four significant peaks that appeared at wavenumbers of $525,576,1182$, and $1429 \mathrm{~cm}^{-1}$ in the FTIR spectrum of the CHFCs are the characteristics of fullerene molecules (Figure $3 \mathrm{~d}$ ). The FTIR band at $2906 \mathrm{~cm}^{-1}$ corresponds to the $\mathrm{C}-\mathrm{H}$ bond stretching vibrations of solvent molecules (mesitylene) remaining CHFCs (Figure 3c,d).

XPS studied the surface composition of the CHFCs. Figure 4 shows the XPS survey spectra and XPS core level C 1s and O 1s spectra with the deconvoluted peaks for CHFCs and $\mathrm{pC}_{60}$. The survey spectra XPS peaks at 284 and $532 \mathrm{eV}$ indicate carbon and nitrogen as the main surface components of the CHFCs and $\mathrm{pC}_{60}$ (Figure $4 \mathrm{a}$ ). From the peak analyses, 
carbon and oxygen were respectively ca. $89.6 \%, 10.4 \%$ for $\mathrm{pC}_{60}$, and $92.6 \%$ and $7.4 \%$ for CHFCs. The presence of oxygen can be attributed to the partially oxidized surface and also due to moisture contamination.
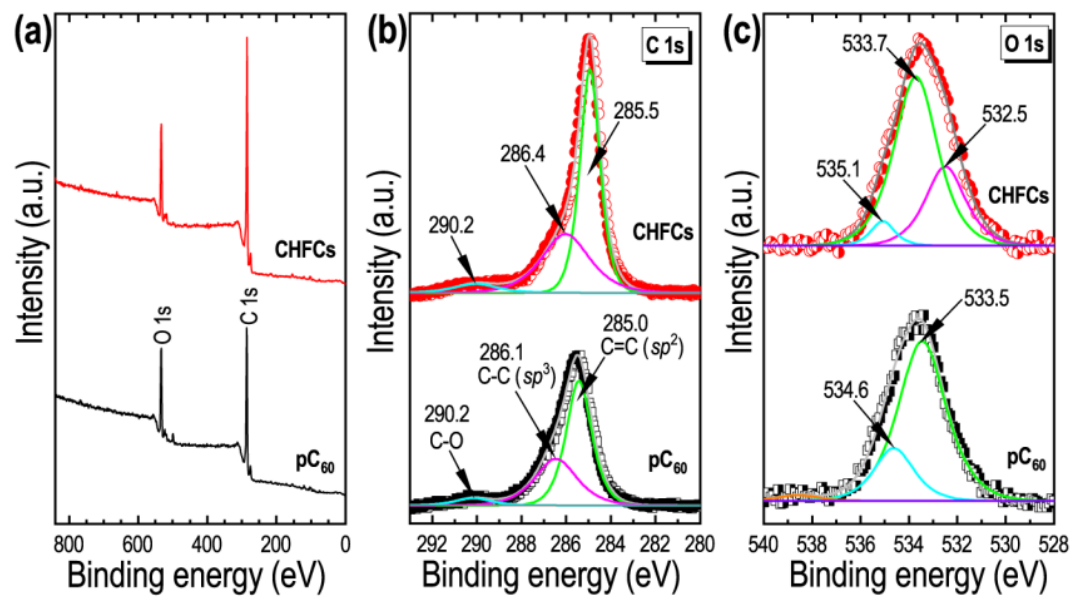

Figure 4. XPS studies of CHFCs and $\mathrm{pC}_{60}$ : (a) XPS survey spectra; (b) $\mathrm{C} 1 \mathrm{~s}$ spectra with the deconvoluted peaks; (c) $\mathrm{O} 1 \mathrm{~s}$ spectra with the deconvoluted peaks.

The high-resolution core level C 1s XPS spectrum of the CHFCs and $\mathrm{pC}_{60}$ could be deconvoluted into three major peaks centered at 285.5 (285.0 for $\mathrm{pC}_{60}$ ), 286.4 (286.1 for $\left.\mathrm{pC}_{60}\right)$, and $290.2 \mathrm{eV}$ corresponding to $\mathrm{C}=\mathrm{C}\left(s p^{2}\right), \mathrm{C}-\mathrm{C}\left(s p^{3}\right)$, and $\mathrm{CO}_{3}{ }^{2-}$ bonding states of carbon (Figure $4 \mathrm{~b}$ ). The high-resolution $\mathrm{O}$ 1s spectrum of $\mathrm{pC}_{60}$ could be deconvoluted into two main peaks with the binding energy of 533.5 and $534.6 \mathrm{eV}$ corresponding to $\mathrm{C}-\mathrm{OH}$, and $\mathrm{C}-\mathrm{O}-\mathrm{C}$ bonding states, while the $\mathrm{O} 1$ s spectrum of the CHFCs could be deconvoluted into three peaks with the peak position of $532.5,533.7$, and $535.1 \mathrm{eV}$ corresponding to $\mathrm{C}=\mathrm{O}$, $\mathrm{C}-\mathrm{OH}$, and $\mathrm{C}-\mathrm{O}-\mathrm{C}$ bonding states (Figure 4c). The surface compositions of the CHFCs and $\mathrm{pC}_{60}$ are similar to other fullerene assemblies [39].

The surface area and porosity of the CHFCs were investigated by using nitrogen adsorption measurements. The nitrogen sorption isotherm of CHFCs suggests porous structures (Figure 5a). While due to the lack of porosity, the nitrogen uptake of $\mathrm{pC}_{60}$ is low. The specific surface area and pore volume of the CHFCs were found to be $57.3 \mathrm{~m}^{2} \mathrm{~g}^{-1}$ and $0.149 \mathrm{~cm}^{3} \mathrm{~g}^{-1}$, respectively.
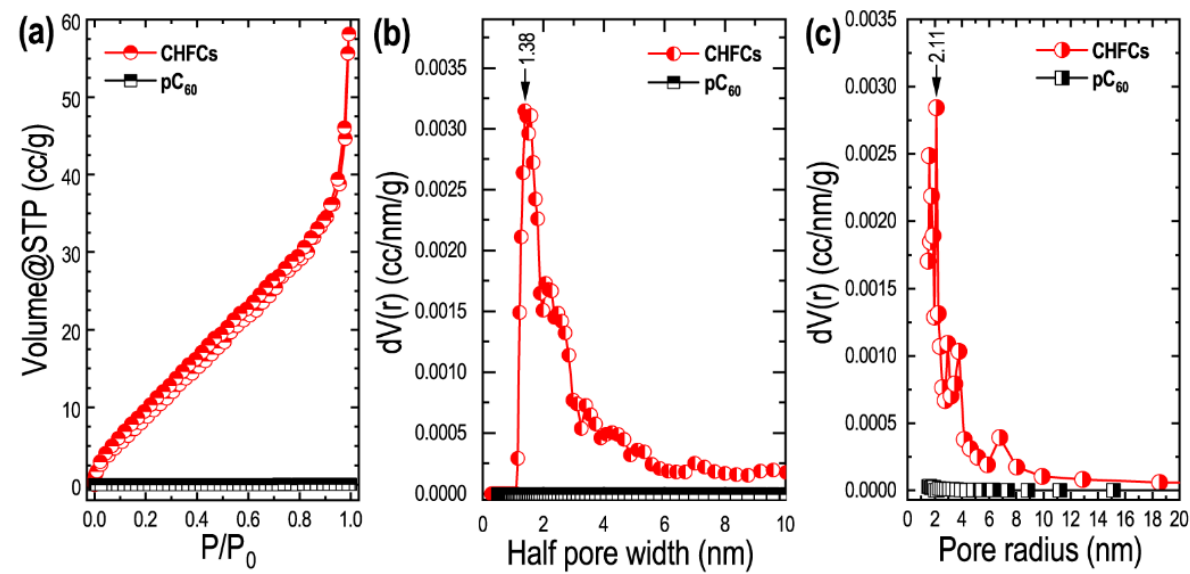

Figure 5. (a) Nitrogen sorption isotherms of CHFCs. Pore size distribution profiles obtained from (b) DFT and (c) BJH method.

The pore size distribution curve obtained from the density functional theory (DFT) method (Figure $5 b$ ) shows a pronounced peak at the half pore width of $c a .1 .38 \mathrm{~nm}$. Some 
pores with sizes in the meso length could also be seen. The pore size distribution profile obtained from the Barrett-Joyner-Halenda (BJH) model (Figure $5 \mathrm{c}$ ) indicates the mesopore structure in the CHFCs with an average pore radius of $2.11 \mathrm{~nm}$. Considering the acetic acid molecular size of $4 \AA$, the well-defined pore structures of the CHFCs are suitable for adsorption of various volatile acid vapors [40].

Self-assembled fullerene nanomaterials are highly hydrophobic and thus present strong van der Waals and hydrophobic interactions with guest molecules. Inspired by the unique corn-husk morphology with porous structures, the CHFCs were employed as sensor material to detect toxic VOCs such as benzene, toluene, formic acid, and acetic acid with quartz crystal microbalance (QCM) techniques. Figure 6a shows a typical example of the time-dependent frequency shifts $(\Delta \mathrm{f})$ of the CHFCs modified QCM electrode upon exposure to different volatile solvents vapors: acetic acid, ethanol, toluene, and formic acid. The frequency shifts swiftly upon exposure to the volatile vapors. At the same time, the frequency returns to the initial frequency when the solvent vapors are removed from the chamber. Thus, the CHFCs exhibited a rapid absorption and desorption process of VOC.
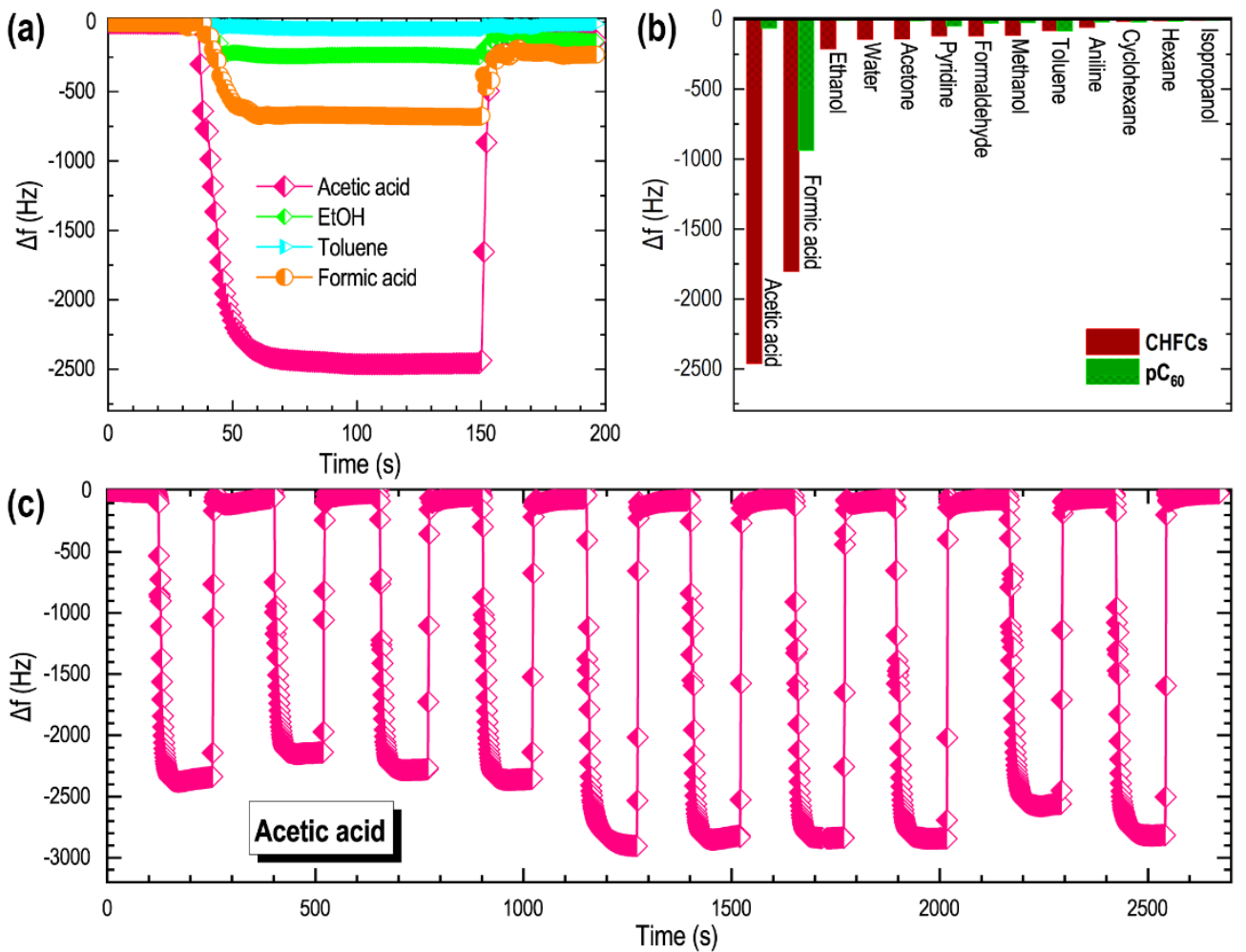

Figure 6. Vapor sensing performance of CHFCs: (a) Frequency shifts $(\Delta f)$ upon exposure of QCM electrode to solvents for typical examples; (b) Summary of sensor performance, and (c) Repeatability test upon expose and removal of acetic acid vapor up to six cycles.

Previous investigations have shown that the fullerene nanomaterials are sensitive to aromatic vapors due to the strong $\pi-\pi$ interactions $[18,41]$. Therefore, the value of frequency shift $(\Delta f)$ greatly depends on the interactions between the guest vapor molecules and the nanostructure, which explains why aliphatic vapors lead to a reasonably slight shift in the frequency. As for the self-assembled CHFCs', the frequency shift caused by the adsorption of aromatic vapors are ca. $85 \mathrm{~Hz}$ (benzene), $80 \mathrm{~Hz}$ (toluene), $56 \mathrm{~Hz}$ (aniline), while the aliphatic vapors are $10 \mathrm{~Hz}$ (hexane), $15 \mathrm{~Hz}$ (cyclohexane), and hydroxyl compound vapors are $10 \mathrm{~Hz}$ (2-propanol), $210 \mathrm{~Hz}$ (ethanol), $114 \mathrm{~Hz}$ (methanol), $143 \mathrm{~Hz}$ (water). Interestingly, the CHFCs are especially sensitive to volatile acid vapor $680 \mathrm{~Hz}$ (formic acid), $2460 \mathrm{~Hz}$ (acetic acid) (Figure 6b). The sensitivity of the CHFCs modified QCM electrode decreases as follows: acetic acid $>$ formic acid $>$ ethanol $>$ water $>$ acetone $>$ pyridine 
$>$ formaldehyde $>$ methanol $>$ toluene $>$ aniline $>$ cyclohexane $>$ hexane $>$ 2-propanol The VOC sensing of the $\mathrm{pC}_{60}$ was also investigated and compared the performance with that of the CHFCs (Figure 6b). Compared to the $\mathrm{pC}_{60}$, the self-assembled CHFCs show extraordinary sensing performance. Due to the unique morphology (hollow structure) with porous architectures, the CHFCs improve the possibility of volatile vapors' selective adsorption. Figure 6c shows the repeatability test results of the QCM electrode recorded upon alternate exposure and removal of acetic acid vapors. The electrode shows sensitive sensing performance with reliable repeatability and reproducibility. Table 1 shows a table comparing the gas-sensing performance of fullerene assemblies as the QCM sensor materials.

Table 1. The VOCs sensing performance of fullerene assemblies.

\begin{tabular}{cccc}
\hline Sample & Selectivity & $\boldsymbol{\Delta} \mathbf{( H z )}$ & Reference \\
\hline FC & Toluene & 206 & 18 \\
\hline HFC & Toluene & 721 & 18 \\
\hline FNR & Toluene & 131 & 35 \\
\hline FNR-EDA & Formic acid & 1758 & 35 \\
\hline FNT & Toluene & 40 & 38 \\
\hline HT-FNT & Benzene & 125 & 38 \\
\hline BMFC & Aniline & 310 & 41 \\
\hline CHFCs & Acetic acid & 2460 & This work \\
\hline
\end{tabular}

FC $=$ Fullerene $C_{70}$ cube; HFC = hierarchical fullerene $C_{70}$ cube; FNR = Fullerene nanorods; EDA = ethylene diamine; FNT = fullerene nanotube; HT-FNT = heat-treated fullerene nanotube; BMFC = bitter-melon shape fullerene crystals.

\section{Discussion}

Molecular sensing of toxic VOCs has received attention and has been deeply investigated to deal with the continuously growing safety concern of the environment and workstation of indoor environments. Low molecular weight acids such as formic acid and acetic acid have been known as essential constituents for environmental contamination, metal corrosion, and food storage. The acetate and formate-based contamination can be traced back to being released from wooden materials [42]. Notably, a high concentration of acetic acid has been monitored to be released from the wooden building materials such as cases, cabinet, draws, shelving, etc. The mechanism is considered to be that the efflorescent salts within the pores or surface of the objects emit acetic acid. Thus, acetic acid is thought to be a threatening component for the indoor environment and ambient air.

Moreover, the air contaminated with acetic acid or formic acid is detrimental to the human respiratory tract, affecting the equilibrium of the interior milieu and the health of organisms. Therefore, based on these fundamental problems, developing novel sensor materials with high sensitivity towards these toxic acid vapors has attracted much attention. Previous investigations have shown that the sensing performance (selectivity and sensitivity) of a sensor depends on the structure and properties of the sensor material. Porous materials offer better sensitivity due to the easy diffusion of guest vapor molecules that can be accommodated in the pore structures. Therefore, the VOC sensing material design needs to engineer the pore architecture of the nanomaterials. Generally, the higher the surface area the better the adsorption of the guest vapors. Therefore, to solve the existing problem of toxic acid vapor contaminations, one needs to design novel nanomaterials with high surface areas and well-defined pore structures essential for high-performance sensing [43-49].

It has been found that fullerene, due to its fused $\pi$-conjugated structure, offers strong van der Walls or $\pi-\pi$ interactions and shows high sensitivity to the aromatic guest vapors. Furthermore, the insertion of micro-mesopore architectures in the host materials promotes 
the diffusion of the guest vapors and enhances the sensing system for the vapor phase. For example, hierarchically-structured fullerene $C_{70}$ cubes consisting of mesoporous nanorods having crystalline pore walls showed excellent sensing performance for aromatic guest vapors due to the strong $\pi-\pi$ interactions with the $s p^{2}$ carbon-rich pores, and easy and fast diffusion through the mesoporous architecture [18]. As a result, the frequency shift caused by the adsorption of aromatic solvents' vapor such as toluene $(721 \mathrm{~Hz})$ and pyridine $(538 \mathrm{~Hz})$ is much higher than the frequency shift caused by the adsorption of aliphatic hydrocarbon vapors hexane $(40 \mathrm{~Hz})$ and cyclohexane $(70 \mathrm{~Hz})$. The sensing sensitivity decreases as toluene $>$ pyridine $>$ ethanol $>$ acetone $>$ cyclohexane $>$ hexane $>$ water. Nevertheless, regardless of the generally accepted trend, it is found in this study that the sensitivity of the CHFCs QCM sensor is higher for acetic acid compared to the aromatic vapors despite the higher saturated vapor pressure of the aromatic solvents. It is anticipated that the hydrogen bonds that hold together acetic acid in the vapor phase in the dimeric species strongly interact with electron-deficient fullerene molecules, enhancing the vapor adsorption in the CHFCs. The sensing sensitivity of the CHFCs sensor decreases as acetic acid $>$ formic acid $>$ ethanol $>$ water $>$ acetone $>$ pyridine $>$ formaldehyde $>$ methanol $>$ toluene $>$ aniline $>$ cyclohexane $>$ hexane $>2$-propanol. This result demonstrates a strong interaction between fullerene and acetic acid vapor, which is promoted by the enhanced diffusion of the acetic acid vapor due to the unique thin tubular wall with a half-opening structure in one end of the CHFCs. Furthermore, the tubular wall comprises a microporous structure with crystalline pore walls (Figure 2e), which provides nano spaces required for the adsorption of acetic acid guest vapors, enhancing the gas sensing performance. On the other hand, due to the lack of well-defined hollow and micro/mesoporous structures, the VOC sensing performance of the $\mathrm{pC}_{60}$ is poor than the self-assembled novel CHFCs.

\section{Conclusions}

In conclusion, the formation of novel corn-husk-shaped fullerene $\mathrm{C}_{60}$ crystals (CHFCs) at the liquid-liquid interface between isopropyl alcohol (IPA) and a saturated solution of $\mathrm{C}_{60}$ in mesitylene under ambient temperature and pressure conditions is successfully demonstrated. The CHFCs exhibit a mixed face-centered cubic $(f c c)$ and hexagonal-close pack ( $h c p$ ) crystal phases with lattice parameters $a=1.425 \mathrm{~nm}, V=2.899 \mathrm{~nm}^{3}$ for $f c c$ and $a=2.182 \mathrm{~nm}, c=0.936 \mathrm{~nm}, a / c$ ratio $=2.33, \mathrm{~V}=3.859 \mathrm{~nm}^{3}$ for $h c p$ phase, respectively. In addition to the hollow structure in one end, the CHFCs possess porous structures with well-defined micro- and mesopore structures. Quartz crystal microbalance (QCM) sensing results show the excellent sensing performance of the CHFCs modified QCM electrode sensitive to acetic acid vapors due to the enhanced diffusion via mesoporous architecture and hollow structure of the CHFCs. Thus, these results demonstrate that in addition to the conventional nanomaterials and molecular nanocarbon such as graphene and carbon nanotubes [50-52], the corn-husk-shaped fullerene $\mathrm{C}_{60}$ crystals have the considerable possibility of developing new functional sensor systems for VOC sensing selective to the aliphatic acid vapors.

Author Contributions: Conceptualization, Z.W., K.A. and L.K.S.; methodology, Z.W., J.S., R.M. and L.K.S.; validation, L.K.S. and K.A.; formal analysis, Z.W., J.S. and L.K.S.; investigation, Z.W., J.S., L.K.S. and R.M.; data curation, Z.W., J.S. and R.M.; writing-original draft preparation, Z.W. and J.S.; writing-review and editing, L.K.S. and K.A.; supervision, L.K.S. and K.A.; project administration, L.K.S. and K.A.; funding acquisition, L.K.S. and K.A. All authors have read and agreed to the published version of the manuscript.

Funding: This research was partially funded by JSPS KAKENHI Grant Number JP20H00392, JP20H00316, JP20K05590, and JP21H04685.

Data Availability Statement: The data presented in this study are available on request from the corresponding author.

Conflicts of Interest: The authors declare no conflict of interest. 


\section{References}

1. Dryahina, K.; Pospisilova, V.; Sovova, K.; Shestivska, V.; Kubista, J.; Spesyvyi, A.; Pehal, F.; Turzikova, J.; Votruba, J.; Spanel, P. Exhaled breath concentrations of acetic acid vapour in gastro-esophageal reflux disease. J. Breath Res. 2014, 8, 037109. [CrossRef]

2. Lvova, L.; Yaroshenko, I.; Kirsanov, D.; Natale, C.D.; Paolesse, R.; Legin, A. Electronic Tongue for Brand Uniformity Control: A Case Study of Apulian Red Wines Recognition and Defects Evaluation. Sensors 2018, 18, 2584. [CrossRef]

3. Magalhães, K.T.; Dragone, G.; de Melo Pereira, G.V.; Oliveira, J.M.; Domingues, L.; Teixeira, J.A.; e Silva, J.B.A.; Schwan, R.F Comparative study of the biochemical changes and volatile compound formations during the production of novel whey-based kefir beverages and traditional milk kefir. Food Chem. 2011, 126, 249-253. [CrossRef]

4. Mas, A.; Torija, M.J.; García-Parrilla, M.d.C.; Troncoso, A.M. Acetic Acid Bacteria and the Production and Quality of Wine Vinegar. Sci. World J. 2014, 2014, 394671. [CrossRef] [PubMed]

5. Mikhailov, A.A. Effect of Low-Molecular Carbon Acids on Atmospheric Corrosion of Metals. Prot. Met. Phys. Chem. Surf. 2009, 45, 757-765. [CrossRef]

6. Lou, X.; Singh, P.M. Role of Water, Acetic acid and Chloride on Corrosion and Pitting Behaviour of Carbon Steel in Fuel-Grade Ethanol. Corros Sci. 2010, 52, 2303-2315. [CrossRef]

7. Greenwald, R.; Fitzpatrick, A.M.; Gaston, B.; Marozkina, N.V.; Erzurum, S.; Teague, W.G. Breath Formate is a Marker of Airway S-Nitrosothiol Depletion in Severe Asthma. PLoS ONE 2010, 5, e11919. [CrossRef]

8. Stavrakou, T.; Müller, J.F.; Peeters, J.; Razavi, A.; Clarisse, L.; Clerbaux, C.; Coheur, P.F.; Hurtmans, D.; De Mazière, M.; Vigouroux, C.; et al. Satellite Evidence for a Large Source of Formic Acid from Boreal and Tropical Forests. Nat. Geosci. 2012, 5, 26-30. [CrossRef]

9. Itoh, T.; Koyama, Y.; Shin, W.; Akamatsu, T.; Tsuruta, A.; Masuda, Y.; Uchiyama, K. Selective Detection of Target Volatile Organic Compounds in Contaminated Air Using Sensor Array with Machine Learning: Aging Notes and Mold Smells in Simulated Automobile Interior Contaminant Gases. Sensors 2020, 20, 2687. [CrossRef]

10. Yuan, Z.; Yang, C.; Gao, H.; Qin, W.; Meng, F. High Response Formic Acid Gas Sensor Based on MoS 2 Nanosheets. IEEE Trans. Nanotechnol. 2021, 20, 177-184. [CrossRef]

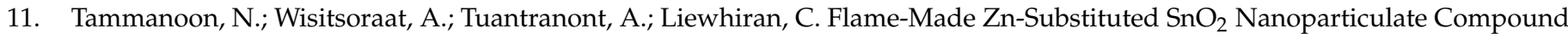
for Ultra-Sensitive Formic Acid Gas Sensing. J. Alloys Compd. 2021, 871, 159547. [CrossRef]

12. Pineau, N.J.; Krumeich, F.; Güntner, A.T.; Pratsinis, S.E. Y-Doped ZnO Films for Acetic Acid Sensing Down to ppb at High Humidity. Sens. Actuators B Chem. 2021, 327, 128843. [CrossRef]

13. Lin, S.; Swager, T.M. Carbon Nanotube Formic Acid Sensors Using a Nickel Bis(ortho-diiminosemiquinonate) Selector. ACS Sens. 2018, 3, 569-573. [CrossRef] [PubMed]

14. Evtugyn, G.; Porfireva, A.; Shamagsumova, R.; Hianik, T. Advances in Electrochemical Aptasensors Based on Carbon Nanomaterials. Chemosensors 2020, 8, 96. [CrossRef]

15. Kroto, H.; Heath, J.; O’Brien, S.; Curl, R.; Smalley, R. C60: Buckminsterfullerene. Nature 1985, 318, 162-163. [CrossRef]

16. Park, C.; Yoon, E.; Kawano, M.; Joo, T.; Choi, H.C. Self-Crystallization of $\mathrm{C}_{70}$ Cubes and Remarkable Enhancement of Photoluminescence. Angew. Chem. Int. Ed. 2010, 49, 9670-9675. [CrossRef]

17. Ehsani, M.; Rahimi, P.; Joseph, Y. Structure-Function Relationships of Nanocarbon/Polymer Composites for Chemiresistive Sensing: A Review. Sensors 2021, 21, 3291. [CrossRef]

18. Bairi, P.; Minami, K.; Nakanishi, W.; Hill, J.P.; Ariga, K.; Shrestha, L.K. Hierarchically Structured Fullerene $\mathrm{C}_{70}$ Cube for Sensing Volatile Aromatic Solvent Vapors. ACS Nano 2016, 10, 6631-6637. [CrossRef]

19. Kalanur, S.S.; Jaldappagari, S.; Balakrishnan, S. Enhanced Electrochemical Response of Carbamazepine at a Nano-Structured Sensing Film of Fullerene- $\mathrm{C}_{60}$ and its Analytical Applications. Electrochim. Acta 2011, 56, 5295-5301. [CrossRef]

20. Thirumalraj, B.; Palanisamy, S.; Chen, S.-M.; Yang, C.-Y.; Periakaruppan, P.; Lou, B.-S. Direct Electrochemistry of Glucose Oxidase and Sensing of Glucose at a Glassy Carbon Electrode Modified with a Reduced Graphene Oxide/Fullerene-C 60 Composite. RSC Adv. 2015, 5, 77651-77657. [CrossRef]

21. Nag, S.; Castro, M.; Choudhary, V.; Feller, J.-F. Boosting Selectivity and Sensitivity to Biomarkers of Quantum Resistive Vapour Sensors used for Volatolomics with Nanoarchitectured Carbon Nanotubes or Graphene Platelets Connected by Fullerene Junctions. Chemosensors 2021, 9, 66. [CrossRef]

22. Wei, L.; Yao, J.; Fu, H. Solvent-Assisted Self-Assembly of Fullerene into Single-Crystal Ultrathin Microribbons as Highly Sensitive UV-Visible Photodetectors. ACS Nano 2013, 7, 7573-7582. [CrossRef]

23. Kim, K.-H.; Ko, D.-K.; Kim, Y.-T.; Kim, N.H.; Paul, J.; Zhang, S.-Q.; Murray, C.B.; Acharya, R.; DeGrado, W.F.; Kim, Y.H.; et al. Protein-Directed Self-Assembly of a Fullerene Crystal. Nat. Commun. 2016, 7, 11429. [CrossRef]

24. Lu, F.; Neal, E.A.; Nakanishi, T. Self-Assembled and Nonassembled Alkylated-Fullerene Materials. Acc. Chem. Res. 2019, 52, 1834-1843. [CrossRef]

25. Ciotta, E.; Prosposito, P.; Tagliatesta, P.; Lorecchio, C.; Stella, L.; Kaciulis, S.; Soltani, P.; Placidi, E.; Pizzoferrato, R. Discriminating between Different Heavy Metal Ions with Fullerene-Derived Nanoparticles. Sensors 2018, 18, 1496. [CrossRef] [PubMed]

26. Liu, H.; Li, Y.; Jiang, L.; Luo, H.; Xiao, S.; Fang, H.; Li, H.; Zhu, D.; Yu, D.; Xu, J.; et al. Imaging As-Grown [60]Fullerene Nanotubes by Template Technique. J. Am. Chem. Soc. 2002, 124, 13370-13371. [CrossRef]

27. Tachibana, M.; Kobayashi, K.; Uchida, T.; Kojima, K.; Tanimura, M.; Miyazawa, K. Photo-Assisted Growth and Polymerization of C60 'nano'whiskers. Chem. Phys. Lett. 2003, 374, 279-285. [CrossRef] 
28. Wang, L.; Liu, B.; Liu, D.; Yao, M.; Hou, Y.; Yu, S.; Cui, T.; Li, D.; Zou, G.; Iwasiewicz, A.; et al. Synthesis of Thin, Rectangular C 60 Nanorods Using $m$-Xylene as a Shape Controller. Adv. Mater. 2006, 18, 1883-1888. [CrossRef]

29. Miyazawa, K.; Kuwasaki, Y.; Obayashi, A.; Kuwabara, M. C 60 Nanowhiskers Formed by the Liquid-liquid Interfacial Precipitation Method. J. Mater. Sci. 2002, 17, 83-88. [CrossRef]

30. Sathish, M.; Miyazawa, K. Size-Tunable Hexagonal Fullerene $\left(\mathrm{C}_{60}\right)$ Nanosheets at the Liquid-Liquid Interface. J. Am. Chem. Soc. 2007, 129, 13816-13817. [CrossRef] [PubMed]

31. Wang, B.; Zheng, S.; Saha, A.; Bao, L.; Lu, X.; Guldi, D.M. Understanding Charge-Transfer Characteristics in Crystalline Nanosheets of Fullerene/(Metallo)porphyrin Cocrystals. J. Am. Chem. Soc. 2017, 139, 10578-10584. [CrossRef]

32. Matsuoka, K.; Matsumura, S.; Akiyama, T.; Yamada, S. Shape Control of Fullerene Microparticles by Using Ethylenediamine. Chem. Lett. 2008, 37, 932-933. [CrossRef]

33. Gavat, O.; Trinh, T.M.N.; Moulin, E.; Ellis, T.; Maaloum, M.; Buhler, E.; Fleith, G.; Nierengarten, J.-F.; Giuseppone, N. 3D Supramolecular Self-Assembly of [60]fullerene Hexaadducts Decorated with Triarylamine Molecules. Chem. Commun. 2018, 54, 7657-7660. [CrossRef] [PubMed]

34. Das, S.; Presselt, M. Progress and Development in Structural and Optoelectronic Tunability of Supramolecular Nonbonded Fullerene Assemblies. J. Mater. Chem. C 2019, 7, 6194-6216. [CrossRef]

35. Hsieh, C.-T.; Hsu, S.-h.; Maji, S.; Chahal, M.K.; Song, J.; Hill, J.P.; Ariga, K.; Shrestha, L.K. Post-assembly dimension-dependent face-selective etching of fullerene crystals. Mater. Horiz. 2020, 7, 787-795. [CrossRef]

36. Ramm, M.; Luger, P.; Zobel, D.; Duczek, W.; Boeyens, J.C.A. Static Disorder in Hexagonal Crystal Structure of $\mathrm{C}_{60}$ at $100 \mathrm{~K}$ and 20 K. Cryst. Res. Technol. 1996, 31, 43-53. [CrossRef]

37. Rana, M.; Bharathanatha, R.R.; Gautam, U.K. Kinetically Stabilized $\mathrm{C}_{60}$-Tolulene Solvate Nanostructures with a Discrete Absorption Edge Enabling Supramolecular Topotactic Molecular Exchange. Carbon 2014, 74, 44-53. [CrossRef]

38. Shrestha, L.K.; Shrestha, R.G.; Yamauchi, Y.; Hill, J.P.; Nishimura, T.; Miyazawa, K.; Kawai, T.; Okada, S.; Wakabayashi, K.; Ariga K. Nanoporous Carbon Tubes from Fullerene Crystals as the $\pi$-Electron Carbon Source. Angew. Chem. Int. Ed. 2015, 54, 951-955. [CrossRef] [PubMed]

39. Arie, A.A.; Chang, W.; Lee, J.K. Effect of Fullerene Coating on Silicon Thin Film Anodes for Lithium Rechargeable Batteries. J. Solid State Electrochem. 2009, 14, 51-56. [CrossRef]

40. Vimalanathan, K.; Shrestha, R.G.; Zhang, Z.; Zou, J.; Nakayama, T.; Raston, C.L. Surfactant-Free Fabrication of Fullerene C60 Nanotubes Under Shear. Angew. Chem. Int. Ed. 2017, 56, 8398-8401. [CrossRef]

41. Furuuchi, N.; Shrestha, R.G.; Yamashita, Y.; Hirao, T.; Ariga, K.; Shrestha, L.K. Self-Assembled Fullerene Crystals as Excellent Aromatic Vapor Sensors. Sensors 2019, 19, 267. [CrossRef]

42. Gibson, L.T.; Watt, C.M. Acetic and Formic Acids Emitted from Wood Samples and Their Effect on Selected Materials in Museum Environments. Corros. Sci. 2010, 52, 172-178. [CrossRef]

43. Al-Hardan, N.H.; Abdullah, M.J.; Abdul Aziz, A.; Ahmad, H.; Low, L.Y. ZnO Thin Films for VOC Sensing Applications. Vacuum 2010, 85, 101-106. [CrossRef]

44. Han, L.; Shi, X.; Wu, W.; Kirk, F.L.; Luo, J.; Wang, L.; Mott, D.; Cousineau, L.; Lim, S.I.I.; Lu, S.; et al. Nanoparticle-Structured Aensing Array Materials and Pattern Recognition for VOC Detection. Sens. Actuators B Chem. 2005, 106, 431-441. [CrossRef]

45. Kaur, N.; Zappa, D.; Ferroni, M.; Poli, N.; Campanini, M.; Negrea, R.; Comini, E. Branch-Like NiO/ZnO Heterostructures for VOC Sensing. Sens. Actuators B Chem. 2018, 262, 477-485. [CrossRef]

46. K1lınç, N.; Şennik, E.; Öztürk, Z.Z. Fabrication of $\mathrm{TiO}_{2}$ Nanotubes by Anodization of Ti Thin Films for VOC Sensing. Thin Solid Films 2011, 520, 953-958. [CrossRef]

47. Şennik, E.; Alev, O.; Öztürk, Z.Z. The Effect of Pd on the $\mathrm{H}_{2}$ and VOC Sensing Properties of TiO $\mathrm{N}_{2}$ Nanorods. Sens. Actuators $B$ Chem. 2016, 229, 692-700. [CrossRef]

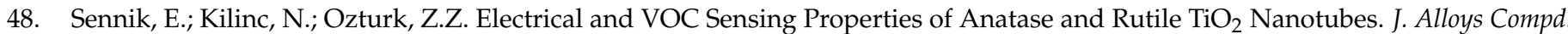
2014, 616, 89-96. [CrossRef]

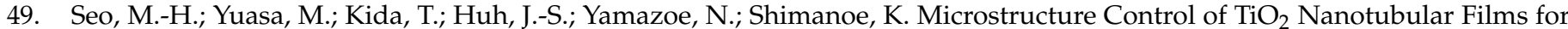
Improved VOC Sensing. Sens. Actuators B Chem. 2011, 154, 251-256. [CrossRef]

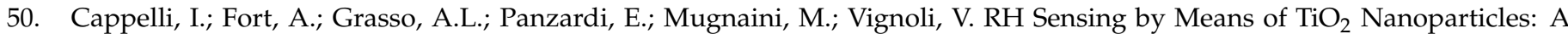
Comparison among Different Sensing Techniques Based on Modeling and Chemical/Physical Interpretation. Chemosensors 2020, 8, 89. [CrossRef]

51. Pandhi, T.; Chandnani, A.; Subbaraman, H.; Estrada, D. A Review of Inkjet Printed Graphene and Carbon Nanotubes Based Gas Sensors. Sensors 2020, 20, 5642. [CrossRef] [PubMed]

52. Love, C.; Nazemi, H.; El-Masri, E.; Abbrose, K.; Freund, M.S.; Emadi, A. A Review on Advanced Sensing Materials for Agricultural Gas Sensors. Sensors 2021, 21, 3423. [CrossRef] [PubMed] 